Rev. salud pública. 13 (2): 339-351, 2011

Ensayo/Essay

\title{
Incorporating equity into developing and implementing for evidence-based clinical practice guidelines
}

\section{Consideraciones de equidad en el desarrollo e implementación de guías de práctica clínica basada en la evidencia}

\author{
Javier Eslava-Schmalbach, Gisella Sandoval-Vargas y Paola Mosquera
}

Clinical Research Institute, Universidad Nacional de Colombia. jheslavas@unal.edu.co, paolamosquera@gmail.com

Received $23^{\text {th }}$ November $2010 /$ Sent for Modification $15^{\text {th }}$ December 2010/Accepted $10^{\text {th }}$ January 2011

\section{ABSTRACT}

Clinical practice guidelines (CPG) are useful tools for clinical decision making, processes standardization and quality of care improvements. The current General Social Security and Health System (GSSHS) in Colombia is promoting the initiative of developing and implementing CPG based on evidence in order to improve efficiency and quality of care. The reduction of inequalities in health should be an objective of the GSSHS. The main propose of this analysis is to argue why it is necessary to consider the incorporation of equity considerations in the development and implementation of clinical practice guidelines based on the evidence. A series of reflections were made. Narrative description was used for showing the arguments that support the main findings. Among them are: 1. Differential effectiveness by social groups of interventions could diminish final effectiveness of CPG in the GSSHS; 2. To not consider geographical, ethnic, socioeconomic, cultural and access diversity issues within the CPG could have a potential negative impacts of the CPG; 3 . Overall effectiveness of GPC could be better if equity issues are included in the quality verification checklist of the guideline questions; 4 . Incorporating equity issues in the process of developing CPG could be cost effective, because improve overall effectiveness of CPG.

Conclusions To include equity issues in CPG can help in achieving more equitable health outcomes. From this point of view CPG could be key tools to promote equity in care and health outcomes.

Key Words: Health, inequalities, practice guidelines as topic, health care sector (source: $\mathrm{MeSH}, \mathrm{NLM}$ ).

\section{RESUMEN}

Las Guías de Práctica Clínica (GPC) son herramientas útiles para la estandarización de los procesos de toma de decisions y los mejoramientos de la calidad del cuidado. El Sistema General de Seguridad Social en Salud (SGSSS) en Colombia está promoviendo 
la iniciativa de desarrollar e implementar GPC basadas en evidencia con la intención de mejorar la eficiencia y la calidad del cuidado. La reducción de las desigualdades en salud debe ser un objetivo del SGSSS. El principal propósito de este análisis es argumentar por qué es necesario considerar la incorporación de las consideraciones de equidad en el desarrollo e implementación de GPC basadas en evidencia. Para ello se hace una serie de reflexiones, usando descripción narrativa para mostrar los argumentos que soportan los principales hallazgos: 1. La efectividad diferencial por grupos sociales de las intervenciones, disminuye la efectividad final de las GPC en el SGSSS; 2. No considerar aspectos como diversidad geográfica, étnica, socioeconómica, cultural y de acceso dentro de las GPC podría tener un impacto negativo potencial de la GPC; 3. La efectividad global de la GPC puede ser mejor si los aspectos de equidad son incluidos en la lista de verificación de calidad de las preguntas de la GPC; 4. Incorporar los aspectos de equidad en el proceso de desarrollo de la GPC puede mejorar la costo efectividad, porque mejora la efectividad global de la GPC.

Conclusiones Incluir la equidad como un aspecto a considerar en la GPC puede ayudar a lograr desenlaces de salud más equitativos. Desde este punto de vista, las GPC pueden ser herramientas que promuevan la equidad en el cuidado y en los desenlaces en salud.

Palabras Clave: Desigualdades en la salud, guías de práctica clínica como asunto, sector de atención de salud (fuente: DeCS, BIREME).

$\mathrm{E}$ quity (from the Latin aequitas, from aequus, equal) has been de fined by some authors as being "consistent equality" (1). It is seen to refer to a state of law in which it is specifically free from bias or favoritism, from a concept of ideal justice according to natural law and being just, having impartiality and equality (2). The International Society for Equity in Health defines it as being the absence of potentially remediable and systematic differences in one or more aspects of health across socially, demographically or geographically defined populations or population subgroups (3). Considering equity within the health setting leads to identifying and analyzing aspects generating or establishing differences, inequalities or disparities between different population groups, which are considered to be avoidable, unnecessary and unjust (4).

Specifically, equity in health care is defined as having equal access to care for the same need, equal use for equal need, and equal quality of care for all (4). Even though this concept is related to the concept of health care provided by the World Health Organization (WHO), it contains a broader vision of what could be considered health care and is basically centered on an attention-based approach. Health care must thus cover such relevant topics as access to promotion and prevention programmes, rehabilitation and healthy life styles. Discussion in these spaces deals with ethical dimensions 
when diagnostic or intervention strategies having differential access are proposed, depending on risk factors. The development of the General Social Security and Health System (GSSHS), created by Law 100 on the 23rd of December 1993 (5), was based on three models: Bismarckian, Neoliberal and Decentralisation (6). This approach sought to integrate optimum conditions for the whole population by improving factors such as entities' efficiency, universality, equity, commitment to provide quality service and autonomy for increasing service quality and resolving problems which become presented. Part of the premise concerned users having the freedom of choice to select a health-promoting or health-providing entity and ensuring quality promoted by regulated competition, in principle by government-controlled entities. Many such qualities of the system have still not become evident within its functioning and, even though in principle coverage has improved, there are still no guarantees of free choice, even less so regarding the quality of the system's universal attention (7).

The initiative for coordinating developments regarding evidence-based clinical practice guidelines (CPG) emerged from the search for improving the efficiency and quality of health system attention, so that they could be used as tools when taking clinical decisions and thus allow processes to become standardized and improve the quality of services when attending patients (8). The availability of CPG also facilitates the homogenization of processes, including those related to their implementation, execution, evaluation and measuring results so that they can be more reliable (8). Including these elements facilitates CPG insertion into GSSHS operation, thus making efficient health resources use more feasible, and improving the quality of health promotion, prevention, attention and results, if such components are included in them. However, providing CPG with these characteristics during their development and implementation does not guarantee that CPG will promote reduced inequity in health per se, unless such component has been intentionally included when developing and implementing them. The following question has emerged from this reflection: "Why must equity be considered within the development and implementation of evidence-based CPG in the GSSHS?". A series of reflections about the importance of equity when developing and implementing CPG and in the GSSHS have thus been undertaken to answer this question. A narrative and argumentative discourse has been used, orientated towards investigating such questioning and its relevance will also be criticized further on, leading to a description of some of the most important points to bear in mind when including considerations of equity and its applicability when implementing the process. 
Reflections have been made within the line of argument related to the poor impact of CPG within the GSSHS, even more so when their effectiveness is seen to be differential by social group, i.e. on the negative potential impact of not including aspects related to equity in CPG, the positive potential impact of CPG on effectiveness when all social groups are involved, the cost of CPG when moving in a scenario of poor effectiveness and the differential impact on health in several social groups.

\section{Poor impact of CPG within the GSSHS, having differential effective- ness by social group}

Studies have shown that CPG have not had the expected impact in some cases due to not having had wide acceptance by users, in this case health professionals and patients $(9,10)$ This becomes even more evident if CPG do not incorporate or represent diagnostic or therapeutic proposals when being constructed and/or implemented, which may be inclusive for different socially categorized groups. This also happens when the plan of benefits is designed to be more inclusive for those having greater payment ability than those having less, thereby causing problems of access and, in turn, CPG adherence. This produces evident inequity in health attention, thereby resulting in differences in health results amongst such types of population. CPG will have greater impact in Colombia, for example, on health service use if the different affiliation regimes have similar resource use. CPG must thus be created which consider the whole spectrum of health prevention, promotion and attention, bearing in mind different social groups' particularities, basing them on the best scientific evidence, in the end having a bearing on improving quality, thus implying a uniform improvement in a population's health. Tugwell et al. (11) have proposed including considerations of equity when evaluating population effectiveness in their iterative ASA model, precisely because it is evident that differential results will be produced regarding a population's health equity when implementing effective strategies in different ways. The differential impact of CPG on social classification categories will make social differences in health and disease much greater, supported by these non-inclusive recommendations made by the very CPG themselves. 
The potential negative impact of not including the topic of equity in CPG

Wherever the geographic place, there will be some degree of diversity regarding health in the area of influence for developing and implementing CPG (i.e. geographic, ethnic, socioeconomic, cultural, access, etc.) which must be considered when developing and implementing them. Not doing so will imply a reduction in coverage (as mentioned in the previous section) and thus in their effectiveness. CPG which do not consider the topic of diversity when formulating their recommendations will thus only have an impact on the population for which the recommendations have been formulated and, when these are favorable, the CPG will favor an increase in inequality between groups having such widely differing social categories and as such inequality is avoidable and unjust it will consequently produce an increase in health care inequity.

The potential positive impact on CPG effectiveness when all social groups are involved

Including all groups of interest when developing and implementing CPG means that social groups will remain in them when broadcasting the recommendations promoted by the guidelines in such a way that the potential negative impact on the intensification of health differences will become minimized. However, involving all possible social groups will increase the work, the cost of the CPG and the time needed for developing and implementing them. It is highly probable that considerations of equity when developing and implementing CPG do not involve actors from some social groups in such a way that the CPG seem to be inclusive when recommendations are published, even though in fact they do not guarantee that implementing them might reduce health care inequalities, depending on value judgments, health care inequities during and after their implementation. Considerations of equity must be included when CPG are being developed, this is key for CPG having a truly positive impact on reducing health inequity and that such criteria should be evaluated as part of the checklist for verifying quality for each of the questions CPG may resolve. It would thus become evident whether potential impacts on equity had been included or rejected in each point in the same way as search strategies or new scenarios might be included or rejected in CPG. CPG could thus have a potential positive impact on health equity, at least regarding those points where they have been considered and, consequently, the overall effectiveness of CPG could also be improved. 
An example of the above could be as follows. Let us consider a population having 4 groups of social categorization (SCI, SC2, SC3 and SC4), having the following percentages of frequency $(40 \%, 30 \%, 20 \%, 10 \%$, respectively). CPG final effectiveness will depend on CPG effectiveness in each group of social categorization in such a way that the mathematical result will be the weighted sum of such focalized effectiveness (equation 1). Assuming, for example, that CPG had $50 \%$ effectiveness in a community but that pertinent questions, considerations and recommendations were centered on CS1 then CPG final effectiveness would change due to the impact focalized on CS1. Equation 1 shows that final CPG effectiveness would be $20 \%$ as the respective considerations making it effective in the other social categories had not been included (equation 3-4).

EFinalCPG $=\Sigma($ EFSCn $) \mathrm{x}(p n)$

(equation 1)

where is CPG final effectiveness, EFSCn is effectiveness in each social category, and pn is the percentage of the population within such social category.

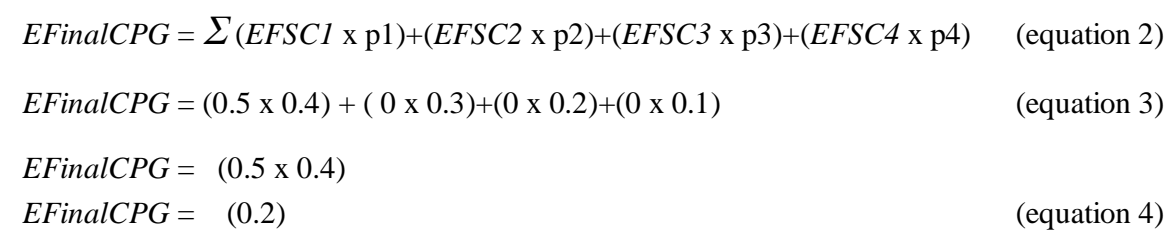

Given that any intervention's effectiveness in the community depends on factors such as initial effectiveness, diagnostic capacity, supplier adherence, patient adherence and coverage, as suggested by Tugwell et al.,(1l) each of these points is relevant in the CPG implementation scenario. The possibility of different values in each of these variables by social category makes understanding the phenomenon more complex, but comes closer to the reality of what happens by implementing health interventions in a community (CPG in this case). Continuing with the mathematical model, effectiveness within each social category will depend on these variables, as shown by equation 5 .

$E S C n=\left(\right.$ EFinitial $\left._{c s n}\right) \times\left(d X_{c s n}\right) \times\left(\right.$ Adhp $\left._{c s n}\right) \times\left(\right.$ Adhpte $\left._{c s n}\right) \times\left(C o v_{c s n}\right) \quad$ (equation 5)

where EFinitial is initial effectiveness, $c s n$ is social class $n(1,2,3,4), d x$ is the diagnosis, Adhp is supplier adherence, Adhpte is patient adherence and $\operatorname{Cov}$ is coverage. 
Based on both equations, Table 1 presents the results of estimating the final effectiveness of CPG which had no differential effectiveness by social category and Table 2 those for another which even though not showing a differential effect on initial effectiveness or diagnostic capacity did have an effect on supplier adherence, patient adherence and coverage by social category.

Table 1. Final CPG effectiveness, considering that there were no differences in implementation by social categories

\begin{tabular}{lcccccccc}
\hline & $\begin{array}{c}\text { Initial } \\
\text { effectiveness }\end{array}$ & $\begin{array}{c}\text { Diagnostic } \\
\text { capacity }\end{array}$ & $\begin{array}{c}\text { supplier } \\
\text { adherence }\end{array}$ & $\begin{array}{c}\text { patient } \\
\text { adherence }\end{array}$ & Coverage & $\begin{array}{c}\text { Final } \\
\text { effectiveness } \\
\text { (equation 5) }\end{array}$ & $\begin{array}{c}\text { Percentage } \\
\text { population }\end{array}$ & $\begin{array}{c}\text { Weighted } \\
\text { effectiveness } \\
\text { (equation 1) }\end{array}$ \\
\hline $\begin{array}{l}\text { Social } \\
\text { category 1 }\end{array}$ & 0.9 & 0.9 & 0.9 & 0.9 & 0.9 & 0.59049 & 0.4 & 0.236196 \\
$\begin{array}{l}\text { Social } \\
\text { category 2 }\end{array}$ & 0.9 & 0.9 & 0.9 & 0.9 & 0.9 & 0.59049 & 0.3 & 0.177147 \\
$\begin{array}{l}\text { Social } \\
\text { category 3 }\end{array}$ & 0.9 & 0.9 & 0.9 & 0.9 & 0.9 & 0.59049 & 0.2 & 0.118098 \\
$\begin{array}{l}\text { Social } \\
\text { category 4 }\end{array}$ & 0.9 & 0.9 & 0.9 & 0.9 & 0.9 & 0.59049 & 0.1 & 0.059049 \\
$\begin{array}{l}\text { CPG real } \\
\text { effectiveness }\end{array}$ & & & & & & & & \\
\hline
\end{tabular}

Table 2. CPG final effectiveness, considering that there were differences in implementation by social category

\begin{tabular}{lcccccccc}
\hline & $\begin{array}{c}\text { Initial } \\
\text { effectiveness }\end{array}$ & $\begin{array}{c}\text { Diagnostic } \\
\text { capacity }\end{array}$ & $\begin{array}{c}\text { Supplier } \\
\text { adherence }\end{array}$ & $\begin{array}{c}\text { Patient } \\
\text { adherence }\end{array}$ & Cove rage & $\begin{array}{c}\text { Final } \\
\text { effectiveness } \\
\text { (equation 5) }\end{array}$ & $\begin{array}{c}\text { Proportion } \\
\text { population }\end{array}$ & $\begin{array}{c}\text { Weighted } \\
\text { effectiveness } \\
\text { (equation 1) }\end{array}$ \\
\hline Social category 1 & 0.9 & 0.9 & 0.9 & 0.9 & 0.9 & 0.59049 & 0.4 & 0.236196 \\
Social category 2 & 0.9 & 0.9 & 0.8 & 0.8 & 0.8 & 0.41472 & 0.3 & 0.124416 \\
Social category 3 & 0.9 & 0.9 & 0.4 & 0.4 & 0.4 & 0.05184 & 0.2 & 0.010368 \\
Social category 4 & 0.9 & 0.9 & 0.3 & 0.3 & 0.3 & 0.02187 & 0.1 & 0.002187 \\
$\begin{array}{l}\text { CPG real } \\
\text { effectiveness }\end{array}$ & & & & & & & & \\
\hline
\end{tabular}

Summarizing this section, and as can be seen, overall CPG effectiveness would be greater if considerations of equity were included in their development and implementation.

\section{Cost of CPG according to effectiveness}

When a health care organism or government entity decides to implement using CPG in health care scenarios it might be expected that standardizing health care promotion, prevention and attention for determined pathologies would have a bearing on improved disease management, better attention and thus better health care results. However, putting CPG into practice implies a potentially high cost which must be assumed by financing organisms, with the hope that this will be seen as being more an investment than an expense, 
in the sense that there will be a positive return on the investment, be this in health results, quality of attention, user satisfaction or savings within the system by reducing futile spending/expenses.

From this viewpoint then CPG having poor effectiveness will not have the expected results in some or all of the aforementioned variables, thereby making CPG development and implementation become yet another expense within the GSSHS. Regarding considerations of a population's cultural, geographic, ethnic or socioeconomic diversity, not considering health equity elements when developing and implementing CPG will result in CPG not having the expected results in such non-included populations and, therefore, their overall effectiveness will become reduced.

CEIFinalCPG $=\frac{\text { CostwithCPG }- \text { EfinalwithCPG }}{\text { CostwithoutCPG-EfinalwithoutCPG }} \quad$ (equation 6)

Equation 6 presents the classic estimation of incremental cost effectiveness (CEIFinalCPG) 12 related to health attention, with the use of CPG and without them, where CostwithCPG is the cost of the whole strategy when CPG are used and CostwithoutCPG is the cost without including CPG. This can also be represented for EfinalwithCPG referring to effectiveness following CPG use and EfinalwithoutCPG referring to overall effectiveness without having used CPG. In the case of a scenario of CPG which has not incorporated considerations of equity in its development and implementation, this would imply greater comparative costs due to the direct cost of having to draw up and implement the CPG. If the fact that overall effectiveness will be lower is added to this (as exemplified in Table 2), then this would mean that the dominant strategy would probably be to not draw up CPG, due to the greater cost associated with poor impact on effectiveness within a particular community. Furthermore, the scenario may become darker if opportunity costs are included within implementation costs (i.e. the cost of actions which could have been implemented and were not as resources were being managed in drawing up and implementing CPG).

In other words, considerations of equity may imply greater "investment" in developing and implementing CPG, even though their greater effectiveness may be promoted by doing so. Not doing so will necessarily reduce their effectiveness and consequently the potential return on the expected investment in health results, quality of attention and/or user satisfaction (i.e. it is probable that the expected savings within a system may not be reflected, 
leading to the conclusion that having drawn up and executed CPG would have been a waste of time and money).

Differential final impact on health in several social groups As insistently mentioned beforehand, it would be expected that the potential impacts of CPG would occur in the same way in the different groups of social classification. However, if there is health inequity regarding the variables which $\mathrm{CPG}$ are aimed at improving in these social groups (before the CPG were developed), then differential CPG effectiveness may be expected when such differential favors the least-favored groups, as happens when dealing with a vertical equity strategy 1 . This may be seen in decreasing performance in populations in which potential CPG impact is expected to be less, when progress has already been achieved in improving health conditions and any additional improvement will imply an incremental cost from this point which would be much greater than when an effective strategy is implemented in a population having poor development conditions $(13,14)$. However, if the CPG promote recommendations or are implemented in such a way that differential effectiveness favors the most advantaged social groups, then CPG would be per se, a tool for delving even deeper into social inequity.

It is evident that CPG promoting improvements or interventions which may be differential within the country, favoring more regions richer and less regions poorer, will lead to increasing social differences regarding this variable within the Country. The same happens if this variable is implemented in a single region, but favors more the inhabitants of localities which are more favored than least favored ones.

On the contrary, CPG promoting strategies leading to reducing mortality in children aged under 5yo, favoring the least favored departments, will have a greater impact on equity in health in Colombia and, possibly, better results in reducing under five mortality rates if a scenario of decreasing effectiveness is assumed $(13,14)$.

\section{Scope of the CPG}

Even though this reflection has been based on the role of considerations of equity in developing and implementing CPG, it is highly convenient to state that CPG are focused on clinical entities aimed at standardizing their prevention, promotion and care processes and making resources use more efficient. The topic of health equity is a "social justice" topic (15) in that it is 
hoped that society promotes a more just society in different ways and that such justice must be reflected in the populations' health. Consequently, considerations of equity have a social perspective whilst CPG have the GSSHS perspective. Even though these represent two different perspectives, society is interested in the GSSHS promoting what is just and not, on the contrary, going deeper into injustices, which already occurs at the level of society. Reflection on incorporating equity within CPG development and implementation thus fits in with such vision.

However, CPG have a maximum expected scope and this is related to the clinical entity on which its action is centered. CPG are not going to resolve other social problem which are explanatory of many health-disease processes and have levels of state action and attention from a determinant point of view. As CPG are designed to have an impact on the mortality of children aged less than five, centering efforts on Acute Diarrheic Disease and Acute Respiratory Insufficiency, then little can be done for improving the mothers' scholastic levels or for improving children's environmental conditions (unhealthy water and overcrowding) unless a perspective is adopted which goes beyond the scope of the CPQ and which ensures that regulating organisms which know them and manage them must be made aware.

Including a strategy for evaluating CPGs' potential impact on equity could eventually avoid emphasizing current health inequity. Some important factors in incorporating considerations of equity should be taken in account for such inclusion: involving the target population and ensuring its participation when designing, posing questions about and developing CPG and implementing and evaluating them; adapting and developing the cultural capacity of suppliers responsible for applying the recommendations contained in the CPG ensuring to a process which is competent and adapted to the target population's cultural signals and thus leading to applying interventions without disparities and having more equitable clinical results; considering the psychosocial and cultural factors which could affect the results of implementing CPG is necessary for making modifications for adjusting the guidelines to the needs of disadvantaged sub-groups; and considering inequities at systemic level from the perspective of social determinants and overall health system actions is orientated towards promoting interventions for confronting risk conduct seen as being an obstacle to healthy life-styles for improving access to preventative and treatment services in the different social groups. 
A particular population's needs, health situation, and/or variables concerning the population, including its socioeconomic level must be taken into account when analyzing CPG implementation (16). Evidence-based medicine strategies should be used when preparing CPGs as these have served as support when taking decisions and as they have spread to all levels of health care (17).

According to the Australian consensus group (2002), three stages are required for including considerations of equity (18):

1. Searching for evidence of barriers or limitation on capacity or opportunities for achieving equal gains in health for different subgroups of population and socioeconomic position associated with factors such as gender, ethnic group, education, occupation, employment, income, area of residencies, life style and housing conditions;

2. Searching the pertinent literature regarding interventions for overcoming the barriers and improving opportunities for achieving greater gains in health; 3 . Synthesizing the evidence identified in previous stages 1 and 2 for developing recommendations contributing towards ensuring equity in different gradients of socioeconomic position, by reducing the barriers so identified.

CPG constitute a fundamental tool for guaranteeing equity in health attention, regarding specific needs leading to the best alternative in clinical decisionmaking, seeking to promote changes in services, aimed at improving quality.

The importance of equity in health service access and use has increased with the reform of the old National Health System (NHS) and with the introduction of the new GSSHS, thereby involving a transformation guaranteeing health and universal access to services for the whole population, interpreting equity as being equality in access to and availability of health services. This would mean talking about equal attention and quality regarding health service needs and use and thus being able to reduce or eliminate factors which may be considered avoidable or unjust (19). Equity has become an important topic when analyzing the GSSHS since it is a tool considering a large number of factors such as health service access and use, service distribution, social participation and users' autonomy of choice. The factors probably inducing inequity in such system would be lack of universal coverage (including a part of the population), the existence of two affiliation regimes (contributory and subsidized) thereby implying fragmented attention and thus problems of exclusion for the population having least income, a differential obligatory health 
plan (POS) for each affiliation regime and the division of individual and collective attention, thereby producing difficulty in providing integral health attention, the action of intermediaries thus inducing greater expenses and inefficiency in managing resources (20-22), copayments and "moderating installments" thus creating barriers regarding access for the poorest sectors of the population. This is based on two background factors: the lack of universality in affiliation and coverage and the problem regarding the model's structure and operation where the affiliation regimes and service provision mechanisms are already differential (23).

Based on the foregoing, it may be concluded that considering equity when developing and implementing CPG bears relative weight going further than involving potential actors in the process and implying reflection about the different potential effectiveness of the interventions proposed in each social group. This means that such differential level must be considered by social categories in terms of diagnostic capacity, supplier and patient adherence and coverage when evaluating the effectiveness of the CPG in a particular community. Including such considerations regarding equity will mean that the CPG's final effectiveness in reality will deal with how far their scope has tried to reach the population and not the effectiveness of the social group given priority when drawing them up

\section{REFERENCES}

1. Bambas A, Casas J. Assesing equity in health: conceptual criteria. Equity and Health, Ocassional Publication \#8. Washington: PAHO, Pan American Health Organization, 2001.

2. Culyer AJ WA. Equity and equality in health and health care. J Health Econ.1993;12(4):431-.57.

3. Casas-Zamora JA, Ibrahim SA. Confronting health inequity: The global dimension. American Journal of Public Health. 2004;94(12):2055-58.

4. Whitehead M. The concepts and principles of equity and health. . WHO Regional Office for Europe, Discussion Paper; 2000.

5. Congreso de la República, República de Colombia. Ley 100 de 1993. Bogotá: Ministerio de la protección social;1993.

6. Hernández M. Propuesta de reforma a la ley 100 de 1993. Opciones sociopolíticas en debate. Revista Gerencia y Política de Salud. 2005;2005(9): 180-90.

7. Várela A, Carrasquilla G, Tono T, Samper B. Asimetria en la información: barreras para la implementación de la reforma de salud en Colombia. Colombia Médica. 2002;33(3):95101.

8. Pardo R, Mosquera P. Manual metodológico para la elaboración y adaptación de guías de práctica clínica basadas en la evidencia. Bogotá: Instituto de Investigaciones Clínicas, Universidad Nacional de Colombia; 2010.

9. Damiani G, Pinnarelli L, Colosimo S, Almiento R, Sicuro L, Galasso R, et al. The effectiveness of computerized clinical guidelines in the process of care: a systematic review. BMC Health Serv Res. 2010;10:2. 
10. Friedman L, Engelking C, Wickham R, Harvey C, Read M, Whitlock KB. The EDUCATE Study: A Continuing Education Exemplar for Clinical Practice Guideline Implementation. Clinical Journal of Oncology Nursing. 2009;13(2):219-30.

11. Tugwell P, de Savigny D, Hawker G, Robinson V. Applying clinical epidemiological methods to health equity: the equity effectiveness loop: British Medical Journal. 2006; 332(7537): 358-361.

12. Petiti D. Advances cost-effectiveness analysis. In: Petiti D, (Ed). Meta-analysis decision analysis and cost-effectiveness analysis. Methods for quantitative synthesis in Medicine. New York: Oxford University Press, 2000:182-201.

13. Fischer J. The law of diminishing returns? More surgery is not always better. Obstet Gynecol. 2009;114(4):718-9.

14. Mold J, Hamm R, McCarthy L. The law of diminishing returns in clinical medicine: how much risk reduction is enough? J Am Board Fam Med. 2010;23(3):371-5.

15. Rawls J. Justicia como equidad. In: Rawls J (Ed) Justicia como equidad. Materiales para una teoría de la justicia. Madrid: Editorial Technos, 1986. p. 18-39.

16. Centro Nacional de Excelencia Tecnológica en Salud. Metodología para la Integración de Guías de Práctica Clínica. México D.F. Secretaría de Salud; 2007.

17. Social MdIP. Por primera vez sistema general de riesgos profesionales cuenta con herramientas de prevención. Bogotá D.C.: Ministerio de la Protección Social; 2007.

18. Cabana MD, Flores $G$ The role of clinical practice guidelines in enhancing quality and reducing racial/ethnic disparities in paediatrics: Paediatric respiratory reviews. 2002; $3(1): 52-58$

19. Barbieri NC, Puente C, Tarragona S. La equidad en el gasto público en salud. La Plata: Universidad Nacional de La Plata; 2002.

20. Barón G. Colombia: Cuenta de Seguridad Social. La Seguridad social en América Latina y el Caribe. Una propuesta metodológica para su medición y aplicación a los casos de argentina, Chile y Colombia. CEPAL- Naciones Unidas. Centrágolo; Mayo de 2009.

21. Pérez V. La tutela y el derecho a la salud. Informe periodo 2006- 2008. Defensoría del Pueblo. Bogotá; 2009.

22. Ronderos MT. Lo mejor y lo más débil del sistema de salud colombiano. Entrevista a expertos internacionales. Revista Semana. 6-7; 2009.

23. Guarnizo-Herreño CC, Agudelo C. Equidad de género en el acceso a los servicios de salud. Rev. salud pública (Bogotá). 2008; 10 sup(1): 44-57.

\section{Referencias: 9,22 Falta el número de} las páginas 